THE LETTERS OF HART CRANE 


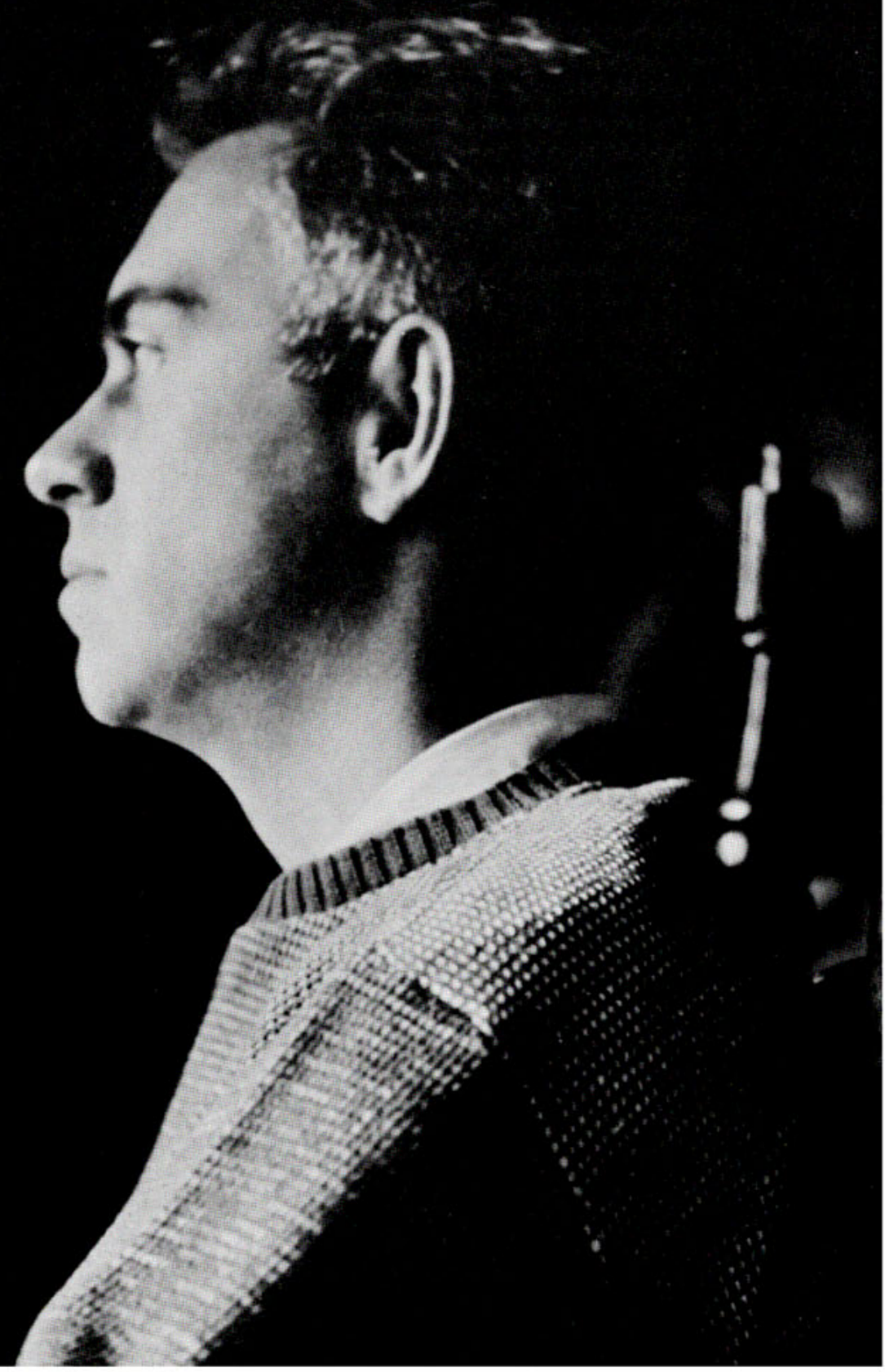

Photo by William Wright, 1931 


\section{THE LETTERS OF}

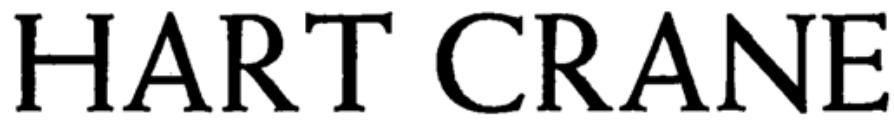

I 9 I6- I 932

EDITED BY BROM WEBER

The imaged Word, it is, that holds

Hushed willows anchored in its glow.

It is the unbetrayable reply

Whose accent no farewell can know.

Berkeley and Los Angeles 1965 
COPYRIGHT, $195^{2}$, BY BROM WEBER

All rights reserved

First California Paper-bound Edition, 1965

MANUFACTURED IN THE UNITED STATES OF AMERICA 